\title{
Effect of sea water and humidity on the tensile and compressive properties of carbon-polyamide 6 laminates
}

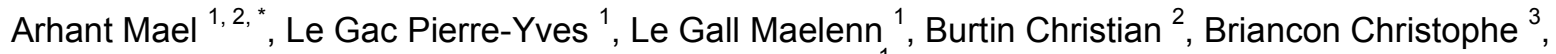 \\ Davies Peter ${ }^{1}$
}

1 IFREMER, Ctr Bretagne, Marine Struct Lab, F-29280 Plouzane, France.

2 Ecole Cent Nantes, Inst Rech Genie Civil \& Mecan GeM, F-44321 Nantes, France.

${ }^{3}$ CETIM, Technocampus EMC2, F-44340 Bouguenais, France.

*Corresponding author : email address : mael.arhant@ifremer.fr

\begin{abstract}
:
Thermoplastic matrix carbon fibre composites offer considerable potential for underwater applications. Various material options exist but there are questions concerning the tension/compressive behaviour and water sensitivity of the less expensive polymers (e.g. polyamides) for these applications. The aim of the current work is to model water diffusion and its effect on the mechanical properties of thick carbon fibre reinforced polyamide- 6 composite cylinders immersed in sea water for deep sea applications. To provide the data for such a model, thin specimens $(2 \mathrm{~mm}$ thick) have been aged under different humidity conditions and tested in tension and compression. As water enters the composite, a significant reduction in the laminate properties is observed. An empirical relationship that links matrix-dominated properties to water content is presented and can be used for modelling purposes.
\end{abstract}

Keywords : Thermoplastic, Carbon fibres, Environmental degradation, Mechanical testing 


\section{Introduction}

More than $70 \%$ of the oceans remain unexplored. With an average depth of over 3800 meters, it is necessary to design exploration devices that are able to withstand high hydrostatic pressures. The lighter these pressure vessels are the more equipment and measuring instruments they can carry, so composites have been used underwater for many years [1]. The use of composites for pressure hulls of underwater vehicles and submarines has been an ongoing research topic for many years, since the early work in the UK by Smith and colleagues in the 1970 's [2]. The use of glass and carbon reinforced thermoset composite materials for deep-sea applications needs a thorough understanding of the behaviour of these materials under hydrostatic pressure. However, the ability to predict the implosion pressures of such materials and under such loadings (bi-axial compression) is not an easy task, as was demonstrated by the results of the World Wide Failure Exercise [3].

Applications for thick thermoplastic cylinders for underwater applications are rarer, even though there is an increasing number of thermoplastic matrix polymers available on the market such as polypropylene (PP), polyamide (PA), polyphenylene sulphide (PPS), polyetheretherketone (PEEK), etc. They offer possibilities for forming by local heating, attractive mechanical properties, good environmental resistance and the potential for end of life recycling. More ductile and reparable by melting, they offer a real potential for greatly improved devices. Studies have been conducted in the USA on carbon/PEEK cylinders [4], [5] and by the author [6] and were found to be very promising as they imploded at comparable pressures to those of their carbon/epoxy counterparts. However, it is not clear to what extent the compressive behaviour of thermoplastic composites in the presence of water will limit the operating depth of an underwater pressure vessel, especially for carbon/polyamide 6 (C/PA6) composites. The latter are attractive as they are much less expensive than composites based on high performance matrix polymers such as PEEK.

The mechanical behaviour of composite materials has been extensively explored in the literature and their performance under tension loads is well understood. However, the behaviour of composite materials subjected to compressive loadings is less clear. Several studies have shown that composite compressive strengths are typically $50-70 \%$ of the tensile strength [7], [8]. Compressive strength is widely acknowledged as one of the most difficult properties to measure in composite materials. Hart et al [9] conducted round robin tests within seven laboratories that used their own test methods and found significantly different results for the same batch of materials. These differences arise from three main aspects: the test method itself, the specimen preparation and the operator's experience in compression testing. This large difference seen in compressive strengths has been and is still the source of overdesigned structures, i.e. heavier structures, which is a problem for the weight 
targeted application. Over the years, several test methods have been standardised. These can be divided into three groups: Shear loading[10], [11], end loading [12] and combined shear and end loading methods [13]. Other non standardised tests have also been proposed such as the ICSTM test fixture [14], [15]. In general, stress concentrations can arise when unsupported sections are short, while buckling may occur when the latter is too long. These can both lead to premature failures. The type of end tab (material, orientation, tapered/non tapered) and the tab-bonding technique also have a non negligible effect on the compressive strength [15], [16]. Moreover, a large scatter in the strain at failure can be observed within the same batch of materials [17]. An alternative approach is to use flexural tests. These include three point bending [18], four point bending [10], [19], [20], pure bending tests [17] and compression/bending tests [21]-[24]. We can use these tests to monitor the side of the specimen that is subjected to compression, in order to investigate the compressive behaviour of the material. For the first two, the stress concentrations found at the loading points can be critical, even though some fixtures have limited their effect [20]. However, in one version of a pure bending test, which will be used here, a compressive load is applied to a pin supported specimen of rectangular cross section. A bending moment $\mathrm{M}$ is induced once the Euler load is reached, thus creating a buckling instability. This test uses a simple fixture, gives reliable results and is also an interesting transition between a material and a structural test. Also, it has been observed that bending tests result in the same type of compressive failure as uniaxial compression tests, especially for thermoplastic composites [25].

The mechanisms leading to compressive failures for carbon fibre reinforced composites are governed by several parameters such as the glass transition of the material and therefore the temperature at which the test is performed [26] and many mechanical properties such as the shear modulus of the matrix [27], [28] and the composite yield shear strength [28], [29]. Therefore, all these properties are of interest when investigating the compressive behaviour of composite materials.

The simplicity of the pin-ended buckling test makes it suitable for the investigation of parameters such as environmental conditions (temperature and humidity). As noted previously, understanding the effect of water ingress on the compressive properties and the associated failure modes is of crucial interest. However, very few results are available in the literature [30] and even less concerning thermoplastic composite materials [31]. Water absorption in polymers is known to have significant effects on their properties. The plasticisation due to water absorption can reduce the glass transition temperature of the polymer [32], [33], and swelling may introduce internal stresses. Polyamides are known to be particularly sensitive to water [34]. Water can also cause a degradation of the fibre/matrix interface [35], [36]. 
The overall aim of the current work is to model water diffusion and its effect on the mechanical properties of thick C/PA6 composite cylinders immersed in sea water for deep sea applications (high hydrostatic pressures and low temperatures ranging from 4 to $15^{\circ} \mathrm{C}$ ). To provide the data for such a model, several properties are needed. Unidirectional composite materials are usually considered to be transversely isotropic. For such materials, five elastic constants are used to describe the behaviour of composite materials: the longitudinal modulus $E_{1}$, the transverse modulus $E_{2}$, the Poisson's ratio $v_{12}$, the shear modulus $G_{12}$ and the transverse shear modulus $\mathrm{G}_{23}$ (or the Poisson's ratio $v_{23}$ ) [37]. Except for the latter $\left(\mathrm{G}_{23}\right)$, all properties were investigated using tensile tests, as a function of homogeneous amounts of water within the laminate. Moreover, because of the targeted application, tests have also been conducted in compression (hydrostatic pressure). These data are not available in the published literature for carbon/polyamide composites. This paper will present the tests and discuss results concerning mechanical properties over a wide range of water contents.

\section{Materials and methods}

\subsection{Materials}

The main material of interest here is a C/PA6 pre-impregnated tape from Celanese ${ }^{\circledR}$ (reference: CFR-TP PA6 CF60-01). It has a fibre volume fraction of $48 \%$ and a 1-ply cured thickness of about 0.19 mm (information given by the supplier). No information is provided by the supplier related to the type of fibre or about the polymer grade. The second material, taken as a reference is a carbon-Polyetheretherketone (C/PEEK) composite supplied by Toho Tenax ${ }^{\circledR}$ (reference: -E TPUD PEEK-HTS45). The fibre volume fraction is $60 \%$ and the tape thickness is about $0.14 \mathrm{~mm}$ (information given by the supplier). The fibre is a HTS45 $12 \mathrm{~K}$ carbon reinforcement from Tenax ${ }^{\circledR}$ and the PEEK matrix is a medium viscosity PEEK matrix from Evonic industries (Vestakeep ${ }^{\circledR}$ 2000). Over the past 30 years, many studies have focused on C/PEEK for structural applications (such as aircraft structures). However, using such a material for the targeted underwater applications is difficult, the latter is 10 times more expensive than the C/PA6 counterpart. Therefore, C/PA6 was chosen here as a low-cost solution.

\subsection{Manufacturing process}

Composite panels were manufactured by hot compression moulding. The C/PA6 panels were manufactured at $230^{\circ} \mathrm{C}$ with a pressure of 5 bar. The C/PEEK panels were manufactured at $420^{\circ} \mathrm{C}$ with a pressure of 10 bar. For both cycles, the cooling rate was chosen to be $20^{\circ} \mathrm{C} / \mathrm{min}$. The manufacturing cycles are presented in 
Figure 1. It should be noted that all $\mathrm{C} / \mathrm{PA} 6$ plies were conditioned at $0 \%$ humidity $\left(40^{\circ} \mathrm{C}\right)$ until the weight stabilised to ensure that each ply was free of water before processing. Each panel that was manufactured was made of 16 plies (about $2 \mathrm{~mm}$ ). Unidirectional $[0]_{16}$ and $[ \pm 45]_{4 s}$ panels were manufactured. It may be noted that the measured ply thickness after press moulding was $0.13 \mathrm{~mm}$ for both materials, i.e. C/PA6 and C/PEEK, which differs from the initial ply thickness.

(a) (b)

Figure 1 : Cycle used for the manufacture of (a) C/PA6 and (b) C/PEEK panels

\subsection{Quality control}


The quality in terms of compaction of plies of the different panels that were manufactured was checked using optical microscopy (polished sections) on a LEICA DM ILM microscope. Polished sections for C/PA6 and C/PEEK are respectively shown in Figure 2.a and Figure 2.b.

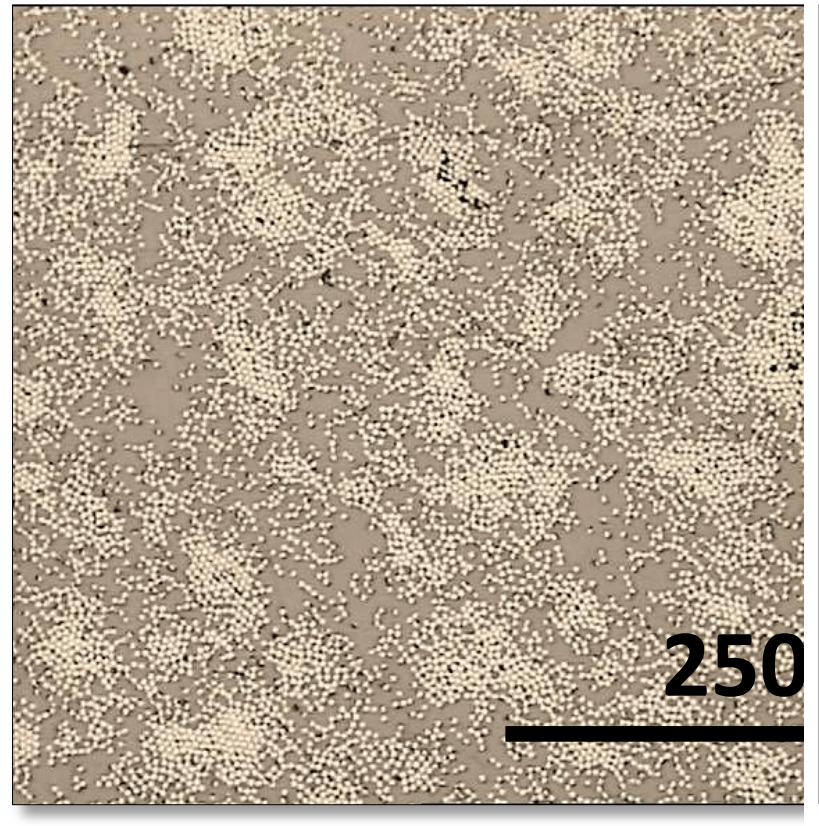

(a)

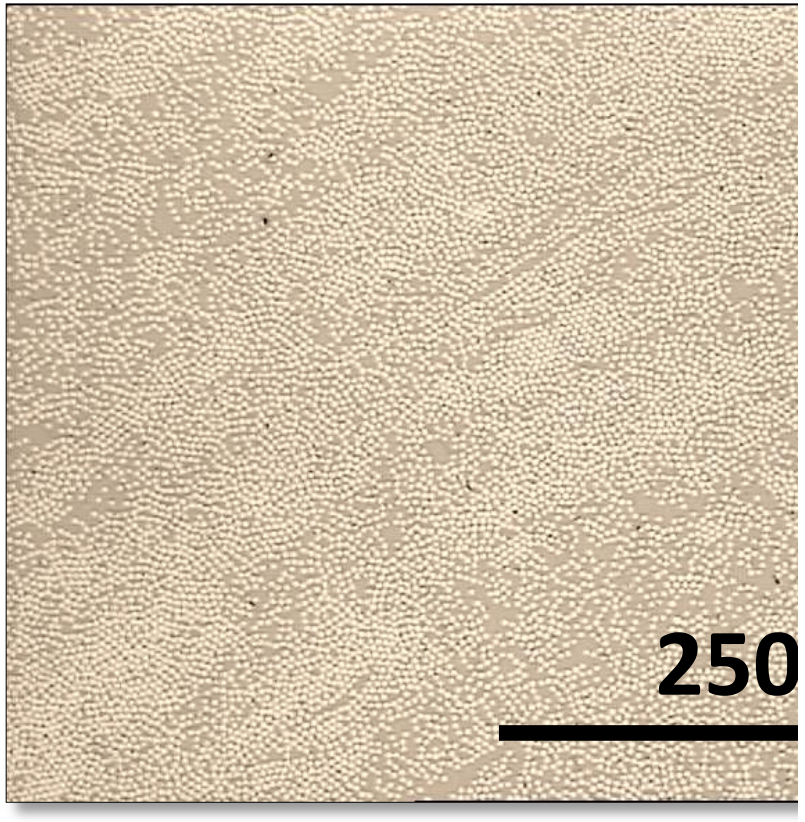

(b)

Figure 2 : Polished sections of unidirectional (a) C/PA6 and (b) C/PEEK specimens

The void contents were determined using the software ImageJ from a mean of 30 images for each composite panel, according to AFNOR NF T 57-109. The degrees of crystallinity $\mathrm{X}_{\mathrm{c}}$ were checked using DSC (Differential Scanning Calorimetry) on Q200 equipment from TA Instrument at a heating rate of $10^{\circ} \mathrm{C} / \mathrm{min}$ from the ambient temperature to $300^{\circ} \mathrm{C}$ for PA6 and $400^{\circ} \mathrm{C}$ for PEEK. However, the degree of crystallinity in thermoplastic composite materials is also dependent on the fibre weight fraction $\mathrm{W}_{\mathrm{f}}$, equation 1 :

$$
X_{c}=\frac{\Delta H_{f}}{\Delta \mathrm{H}_{\mathrm{f}}^{0} \times\left(1-\mathrm{W}_{\mathrm{f}}\right)} \times 100
$$

where $\Delta \mathrm{H}_{\mathrm{f}}$ is the enthalpy of fusion of the polymer and $\Delta \mathrm{H}_{\mathrm{f}}{ }^{0}$ the theoretical enthalpy of fusion for a $100 \%$ crystalline material (taken to be $188 \mathrm{~J} / \mathrm{g}$ for PA6 [38], $130 \mathrm{~J} / \mathrm{g}$ for PEEK [38]). After each DSC measurement, the resin in each sample was burnt-off in TGA (Thermo-Gravimetric Analysis) on SDTQ600 equipment from TA Instrument, in order to obtain the fibre weight fraction $\mathrm{W}_{\mathrm{f}}$ from ambient temperature to $800^{\circ} \mathrm{C}$ at $20^{\circ} \mathrm{C} / \mathrm{min}$ under Nitrogen flow. This temperature was then held for 120 minutes to make sure that all the matrix was removed. Density measurements were also made with a helium pycnometer to obtain the fibre 
volume fraction $\mathrm{V}_{\mathrm{f}}$ of each composite. For each measurement, three samples were used at each time. The results are presented in Table 1 :

Table 1 : Evaluation of the fibre volume fraction, degrees of crystallinity and void contents for the C/PA6 and C/PEEK panels with associated coefficient of variation

\begin{tabular}{cccccc}
\hline Material & $\boldsymbol{\rho}[\mathbf{g} / \mathbf{c m} 3]$ & $\mathbf{W}_{\mathbf{f}}[\mathbf{\%}]$ & $\mathbf{V}_{\mathbf{f}}[\%]$ & $\mathbf{X}_{\mathbf{c}}[\%]$ & Void content [\%] \\
\hline Carbon/Polyamide 6 & 1.46 & $58 \pm 2 \%$ & $49 \pm 2 \%$ & $35.3 \pm 1 \%$ & $0.9 \pm 22 \%$ \\
Carbon/PEEK & 1.57 & $66 \pm 3 \%$ & $60 \pm 3 \%$ & $28.1 \pm 6 \%$ & $0.6 \pm 17 \%$ \\
\hline
\end{tabular}

\subsection{Mechanical tests}

After processing, each panel was end-tabbed and then cut with a water cooled diamond disc to the chosen dimension (precision of $\pm 0.5 \mathrm{~mm}$ ). The end tabs are $[ \pm 45]_{3}$ glass/epoxy laminates manufactured by hand lay-up. These tabs were tapered to reduce stress concentrations. These were bonded to the different laminates with a Loctite 406 glue after a Loctite 770 surface treatment, specifically developed for thermoplastic materials. The tabs have a length of $50 \mathrm{~mm}$ and a thickness of $2 \mathrm{~mm}$. At least four specimens were tested for each condition and the results are averaged. The modulus values were determined in the range from 0.1 to $0.3 \%$ strain. All mechanical tests were performed in a relative humidity and temperature controlled laboratory $(50 \pm 5 \% \mathrm{RH}$, $\left.21 \pm 2^{\circ} \mathrm{C}\right)$

\subsubsection{Tensile tests}

Tensile tests in the longitudinal and transverse direction were performed according to ASTM D 3039. The moduli were obtained using an extensometer of 50mm gauge length. The dimensions of the specimens were $(250 \times 25 \times 2) \mathrm{mm}^{3}$. To obtain the Poisson "s ratio $v_{12}$, bi-axial strain gauges of $10 \mathrm{~mm}$ gauge length were bonded to the specimen. The latter were also used for the determination of the shear modulus $\mathrm{G}_{12}$ on $\pm 45^{\circ}$ specimens according to ASTM D 3518. The dimensions were $(200 \times 20 \times 2) \mathrm{mm}^{3}$. Shear strength was taken to be the stress at $2 \%$ shear strain. The cross head speed was $2 \mathrm{~mm} / \mathrm{min}$ for tensile and shear tests.

\subsubsection{Compression tests}


Initially, a standard test method, ISO 14126 was used for the compression test. Tests were performed at $1 \mathrm{~mm} / \mathrm{min}$. The specimen dimensions were $(110 \times 10 \times 2) \mathrm{mm}^{3}$. However, as will be shown below, strength values from this test were quite low so a second non-standard pin-ended buckling test was subsequently used to evaluate water effects, Figure 3. These tests were performed at $10 \mathrm{~mm} / \mathrm{min}$ in order for test times to be similar for the two tests (and limit water evaporation in subsequent tests after aging). Strain gauges were bonded at the centre of the compressive and tension sides of the specimen to measure strain (gauge length is $10 \mathrm{~mm}$ ). The specimen dimensions are $(250 \times 25 \times 2) \mathrm{mm}^{3}$.

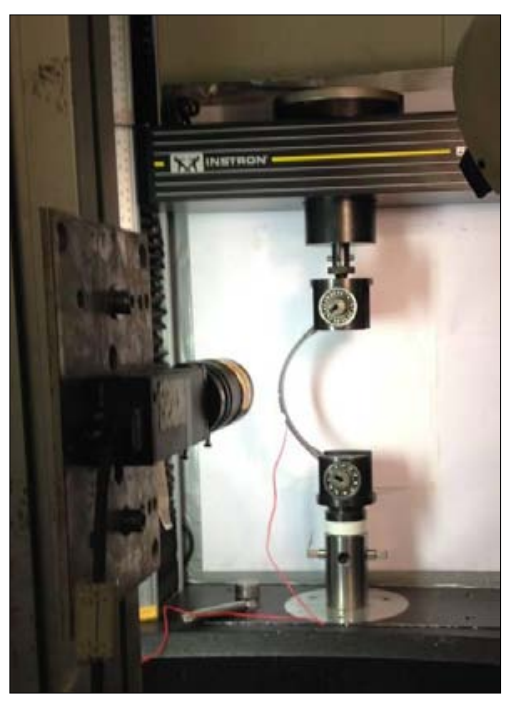

(a)

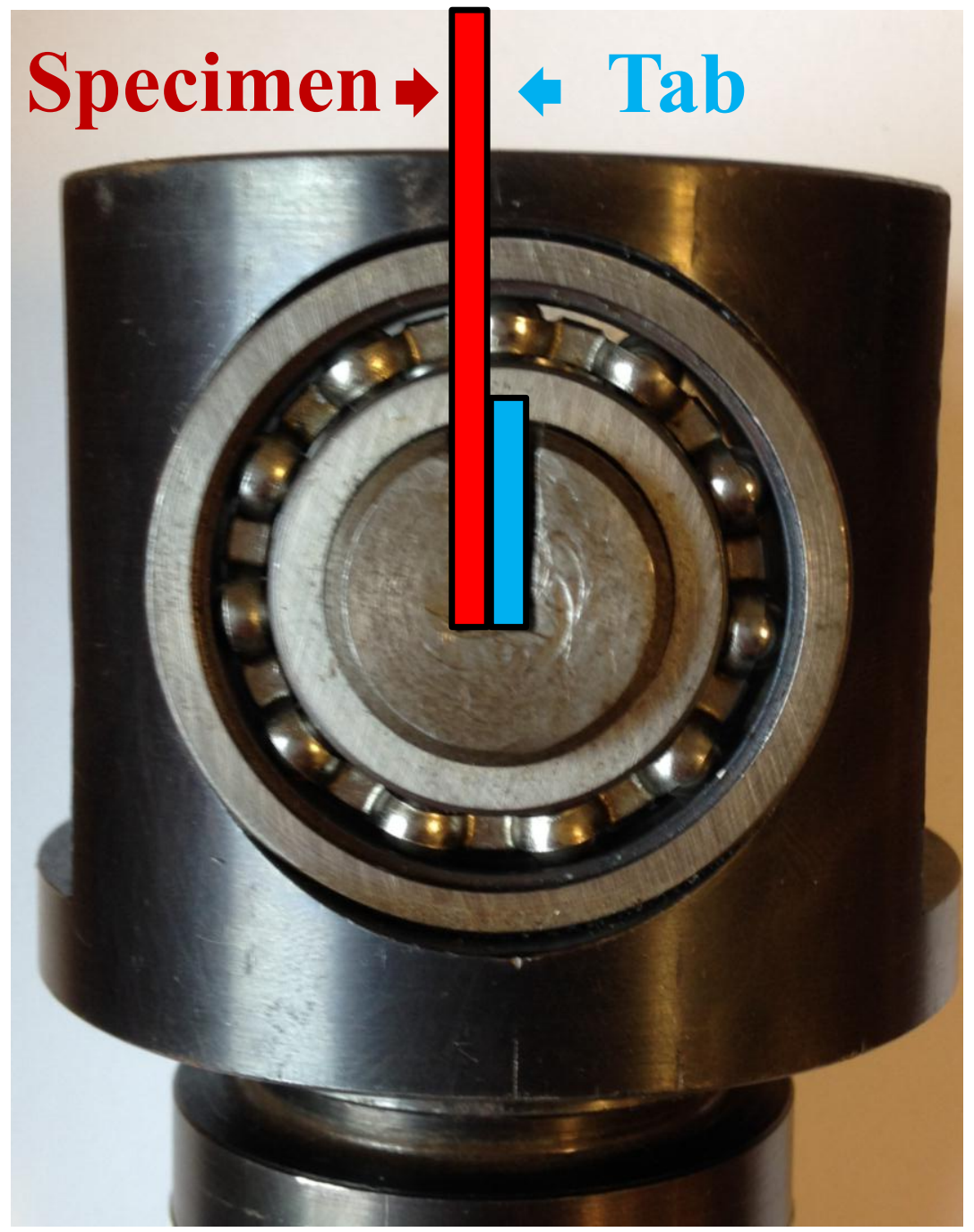

(b)

Figure 3 : (a) Pin-ended buckling test fixture (b) Detail of fixture showing eccentricity of the specimen in the fixture

In the post-buckling stage, the bending moment $\mathrm{M}$ in N.mm is defined by equation 2 : 


$$
M=P . \delta
$$

where $\mathrm{P}$ is the applied load in $\mathrm{N}$ and $\delta$ the lateral deflection at mid-span in $\mathrm{mm}$. The latter is recorded by the help of a digital camera throughout the test as shown in Figure 3.a. The bending stress $\sigma_{b}$ at the centre of the specimen and the compressive stress due to the pure axial load $\sigma_{\mathrm{c}}$ define the final equation 3 .

$$
\sigma=\sigma_{b}+\sigma_{c}=\frac{6 \cdot P \cdot \delta}{b \cdot h^{2}}+\frac{P}{b \cdot h}
$$

Where $b$ and $h$ are respectively the width and thickness of the specimen in $\mathrm{mm}$. As for the tensile modulus, the compressive modulus was then determined in the $0.1-0.3 \%$ strain range.

This equation is a simplified expression, based on a number of assumptions such as identical tensile and compressive behaviour and a linear response. The consequences of these assumptions will be discussed in the result section below. However, it should be noted that there are fundamental differences between pin-ended buckling and standard compression tests. The former is a flexural test which introduces a strong strain gradient while the latter should provide a constant strain across the test section. It has been shown that the presence of a strain gradient results in higher compressive strain at failure [39], [40]. This has been attributed to less highly loaded fibres below the compressed specimen surface, which provide support to limit fibre micro-buckling. As a result it is not possible to compare results from the pin-ended buckling test directly with those from pure compression tests.

\subsection{Aging}

The water absorption was determined from the weight evolution of square samples $(50 \times 50 \times 2) \mathrm{mm}^{3}$ at different temperatures, $40^{\circ} \mathrm{C}$ for PA6 and $80^{\circ} \mathrm{C}$ for PEEK (below the dry $\mathrm{T}_{\mathrm{g}}$ of each matrix). The different samples have been immersed in natural renewed sea water from Brest estuary or conditioned under different humidity conditions. The aim is to quantify the influence of environment on the mechanical properties. The mass gain was followed by periodic weighing of the different specimens on a Sartorius LA310 S balance having a precision of $0.1 \mathrm{mg}$. Before each measurement in immersion, the water on the surface of the specimen was wiped off with a paper towel. For each measurement, three samples were used at each time. The water content, $M(t)$ in wt.\% of a sample is defined as follows, equation 4 :

$$
M(t)=\frac{m(t)-m_{0}}{m_{0}} .100
$$

Where $\mathrm{m}(\mathrm{t})$ is the mass of the sample at a time $\mathrm{t}$ and $\mathrm{m}_{0}$ the initial mass of the sample. Prior to water exposure, all the samples were conditioned at $0 \%$ relative humidity at $40^{\circ} \mathrm{C}$ until their weight stabilised. 
Controlled humidity chambers were used to investigate the effect of water content at saturation on the overall properties of a $2 \mathrm{~mm}$ thick specimen. Different humidities were chosen: $0,33,63$ and $75 \%$ relative humidities (RH). Saturated salt solutions were used to obtain these humidities: Magnesium chloride for 33\%RH, ammonium nitrate for $63 \% \mathrm{RH}$ and sodium chloride for $75 \% \mathrm{RH}$. Greenspan [41], has shown that these solutions could be used to reach the given humidity levels. To do so, all the salt solutions were prepared at $50^{\circ} \mathrm{C}$. For each solution, the given salt was slowly added until the salt did not dissolve itself in the solution. It should be noted that for each solution of interest, the relative humidity was checked periodically (twice a week) all along the aging process. These were placed inside desiccators inside an oven maintained at $40^{\circ} \mathrm{C}\left( \pm 0.5^{\circ} \mathrm{C}\right)$.

After water absorption, dynamic mechanical analyses were performed on $\mathrm{DMA}^{+} 150 \mathrm{~N}$ equipment from Metravib to obtain the glass transition temperatures of the composite. The latter was taken as the tan $\delta$ peak. Measurements were made in tensile mode on unidirectional samples of dimensions $(30 \times 15 \times 2) \mathrm{mm}^{3}$ tested under transverse tension at $2^{\circ} \mathrm{C} / \mathrm{min}$ over the temperature range from $-100^{\circ} \mathrm{C}$ to $150^{\circ} \mathrm{C}$ for the carbon-Polyamide 6 laminates and $25^{\circ} \mathrm{C}$ to $250^{\circ} \mathrm{C}$ for the carbon/PEEK samples. The frequency was $10 \mathrm{~Hz}$ and the dynamic strain amplitude was $2 \cdot 10^{-4}$.

\section{Results and discussion}

First the water diffusion results will be presented, followed by the effect of water diffusion on the glass transition temperature and the mechanical properties (in tension, in plane-shear and compression). It should be noted that these types of results are not found in the literature, more especially in such a wide range of wet conditions. Some studies have used continuous C/PA6 laminates and performed mechanical tests for design purposes [42] but without any aging process. Other studies investigated the effect of aging on the mechanical properties of C/PA6 but without using tests which enable data to be used for designing purposes (ILSS, three point bending, etc.) [43], [44]. Also, in the latter, aging was conducted at high temperatures (60 and $\left.80^{\circ} \mathrm{C}\right)$ for long exposure times, which is known to cause hydrolysis for polyamides [45], and is not the purpose of the current paper. Therefore, the data that are presented here correspond to aging at a lower temperature and provide essential results for the design of composite cylinders immersed in extreme conditions.

This study only considers the effect of homogeneous amounts of water within the laminate saturated in different wet conditions, in order to directly link the mechanical properties to a given water content. 


\subsection{Water diffusion}

Water uptake measurements have been performed in order to characterise diffusion kinetics. Given the low voids contents in these materials, the water ingress is assumed to concern only the matrix. In Figure 4.a and Figure 4.b, the water uptake curves for C/PA6 and C/PEEK samples are plotted as a function of the square root of conditioning time divided by the sample thickness. Except for the immersion of carbon/polyamide 6 samples in sea water, all weight gains can be modelled as Fickian diffusion. Times to fully saturate the samples ranged from 1 to 5 months. This can be characterised by a diffusion coefficient $\mathrm{D}$ and a mass at saturation $\mathrm{M}_{\infty}$. The diffusion coefficient $\mathrm{D}$ can be calculated from the initial linear part of the sorption curve where $\frac{M(t)}{M} \leq 0.5$, eq. 5 [46].

$$
D=\frac{\pi}{16} \cdot \frac{h^{2}}{t}\left(\frac{M(t)}{M}\right)^{2}
$$

Where $\mathrm{h}$ is the sample thickness in $\mathrm{mm}$ and $\mathrm{t}$ the immersion time in $\mathrm{s}$.

(a)

(b)

Figure 4 : Water uptake curves for (a) Carbon/Polyamide 6 specimens conditioned at 33, 63 and $75 \%$ RH and immersed in sea water, all at $40^{\circ} \mathrm{C}$ and (b) Carbon/PEEK specimens immersed in sea water at $80^{\circ} \mathrm{C}$

At high water activities (immersion), it is known that the water diffusion in polyamide 6 is not Fickian [47]. However, to a first approximation, an apparent coefficient of diffusion is presented in Table 2 together with the diffusion coefficients and weights at saturation for the other conditions. 
Table 2 : Diffusion coefficients and mass at saturation for the samples of interest (*starred result: apparent coefficient of diffusion) with associated coefficient of variation

\begin{tabular}{|c|c|c|c|c|}
\hline Material & Conditioning & $\mathbf{D}\left[\mathrm{m}^{2} / \mathrm{s}\right]$ & Ms [\%] & Temperature $\left[{ }^{\circ} \mathrm{C}\right]$ \\
\hline \multirow{4}{*}{ Carbon-Polyamide 6} & $33 \%$ Humidity & $1.7 .10^{-13} \pm 12 \%$ & $0.31 \pm 3 \%$ & \multirow{4}{*}{40} \\
\hline & $63 \%$ Humidity & $1.9 .10^{-13} \pm 24 \%$ & $1.11 \pm 4 \%$ & \\
\hline & 75\% Humidity & $2.2 .10^{-13} \pm 17 \%$ & $1.36 \pm 2 \%$ & \\
\hline & Sea Water* & $4.8 .10^{-13} \pm 5 \%$ & $3.01 \pm 1 \%$ & \\
\hline Carbon-PEEK & Sea Water & $2.6 .10^{-13} \pm 18 \%$ & $0.17 \pm 6 \%$ & 80 \\
\hline
\end{tabular}

Results from water absorption show that the C/PA6 specimens absorb a much higher quantity of water than the C/PEEK. The C/PA6 specimens immersed in sea water absorb $3 \%$ of water by weight during aging compared to 0.17 percent for the C/PEEK. Also, the diffusion coefficients and saturation weights increase for the C/PA6 specimens conditioned at increasing humidity levels. Published results from Taktak et al. [48] and Do et al. [49] are grouped in the following table, Table 3, and are compared to the values found in this work. Only the water uptake in the matrix is considered here.

Table 3 : Comparison with published values for PA6 polymer and composite water uptake

\begin{tabular}{cccc}
\hline Reference & $\begin{array}{c}\text { Water } \\
\text { uptake (\%) }\end{array}$ & $\begin{array}{c}\text { Fibre weight } \\
\text { content (\%) }\end{array}$ & $\begin{array}{c}\text { Water uptake in the } \\
\text { matrix only (\%) }\end{array}$ \\
\hline Taktak et al [48] & $/$ & 0 & 8 \\
Do et. Al [49] & 7.1 & 20 & 8.9 \\
Current paper & 3.0 & 60 & 7.5 \\
\hline
\end{tabular}

The values are slightly lower here, but similar to published values. The PA6 matrix in our work is a commercial formulation. However, thermo-gravimetric analysis indicated no additional fillers apart from the carbon fibres.

\subsection{Effect of water ingress on the glass transition temperature $\left(T_{g}\right)$}

Water sorption in polymers can lead to different types of modification. One can lead to an increase in the chain mobility as water enters the polymer. This phenomenon, plasticising, is known to be reversible and 
decreases the glass transition temperature [34]. Others are irreversible and involve chain scission such as hydrolysis and oxidation [45], but these are not the purpose of the subject of the current paper. Concerning the former, results from dynamic mechanical analyses (DMA) conducted on the composite specimens with homogeneous water distributions following saturation under different humidity conditions are presented in

Figure 5. The DMA plot in the dry state in also presented in Figure 5.b.

(a)

Figure 5 : (a) Decrease in glass transition temperature in C/PA6 specimens saturated at different humidity conditions (b) DMA plot in the dry state

From this result, it is clear that there is a very significant decrease in $\mathrm{T}_{\mathrm{g}}$ from $66 \pm 1^{\circ} \mathrm{C}$ in the dry state to $-12 \pm 1{ }^{\circ} \mathrm{C}$ when the specimen is fully saturated with water. As water enters the material, the glassy amorphous phase of the polymer goes into the rubbery state because of the increase in chain mobility. This phenomenon is reflected in the glass transition temperature of the polymer, and we could expect a strong effect on the mechanical properties, especially when the glass transition drops below the test temperature $\left(21^{\circ} \mathrm{C}\right)$. This decrease in $T_{g}$ can lead to a significant loss in stiffness and an increase in the strain failure for neat PA6 [48]. The question that is now of interest is whether the same trend is observed for composite materials tested in different directions.

It should be noted that the same analyses were performed on the PEEK specimens before and after sea water aging. No differences in $\mathrm{T}_{\mathrm{g}}$ were observed $\left(177 \pm 2^{\circ} \mathrm{C}\right.$ before aging and $174 \pm 3^{\circ} \mathrm{C}$ when saturated). 


\subsection{Effect of water on the tensile properties}

This section will present results from tensile tests performed on specimens with no water profiles (homogeneous amounts of water) after saturation in different environments. These results are essential for design purposes and will be used as a baseline. The strain gauges needed for each test were bonded one by one immediately before testing. The test was then conducted within 30 minutes to minimise evaporation of water.

First, tests were conducted along the fibre direction in order to obtain the longitudinal modulus $\mathrm{E}_{1}$ and Poisson"s ratio $v_{12}$. Examples of results are presented in Figure 6.a and the evolution of the Poisson"s ratio with water aging is shown in Figure 6.b.

(a)

(b)

Figure 6 : Effect of water on (a) the longitudinal and transverse strains under tensile loading (b) Poisson"s ratio $v_{12}$ for $\mathrm{C} / \mathrm{PA} 6$ specimens

No differences concerning the longitudinal modulus are observed, the modulus having a mean value of $106 \mathrm{GPa}$. This result is not very surprising as the behaviour of unidirectional composite materials tested along the fibre direction is highly fibre dominated. It should be noted that no longitudinal tensile stresses at failure are presented in this work. The stress at failure in the dry state was found to be $1808 \pm 132 \mathrm{MPa}$ with a typical fibre pullout failure mode. However, the failure modes observed for the specimens saturated in wet conditions were not valid because of an end tab debonding problem. When the tabbed specimens were aged inside the desiccators and water tanks, the quality of the bond between the end tabs and the composite decreased and invalid 
(premature) failure modes were observed. It can be noted that despite this problem, all failures stresses of wet samples were found to be higher than $1000 \mathrm{MPa}$.

The results concerning the changes in the Poisson "s ratio as a function of water content are quite different to those for the longitudinal modulus. The Poisson's ratio increases from 0.36 to values higher than 0.4 for water contents higher than $1 \%$ and then seems to stabilise, Figure 6.b. The opposite trend is then observed for the shear properties conducted on $\pm 45^{\circ}$ laminates, Figure 7 .

Figure 7 : Influence of water uptake on shear stress versus $\pm 45^{\circ}$ strain plots

First, the shear modulus decreases from 2.4 GPa to 1.3 GPa and appears to reach a plateau for water contents above $1 \%$. Second, the same trend is observed for the shear strength with a $\tau_{12}$ decreasing from $37 \mathrm{MPa}$ to $22 \mathrm{MPa}$ from 0 to $1 \%$ in water content and then stabilising beyond $1 \%$. In a similar way to the results for Poisson's ratio, it seems that a change in the behaviour is observed for water contents higher than $1 \%$.

The third type of tests is transverse tensile on unidirectional laminates as a function of water content. Examples of stress-strain plots are presented in Figure 8. 
Figure 8 : Transverse tensile $\left(90^{\circ}\right.$ to fibres) test curves for C/PA6 specimens saturated under different humidity conditions

These curves clearly indicate that there is a decrease in both stiffness and strength as a function of water content, and an increase in the strain at failure. This result is very similar to what is usually observed on neat PA6 [48] as transverse tensile tests are matrix dominated. It may be noted that the transverse tensile strength at failure is quite low (even in the dry state) compared to the C/PEEK counterpart that is used as a reference ( $25 \pm 2$ $\mathrm{MPa}$ for $\mathrm{C} / \mathrm{PA} 6$ and $83 \pm 8 \mathrm{MPa}$ for $\mathrm{C} / \mathrm{PEEK})$.

Finally, concerning the aging behaviour of C/PEEK laminates subjected to tensile tests, several authors showed that the mechanical properties are not affected by sea water when the specimens are fully saturated [31], unlike for C/PA6 as we just observed.

\subsection{Effect of water on the compressive properties}

First, the compressive strength was obtained using two different test methods. Then, the effect of water content on the compressive properties is presented for C/PA6 UD panel.

\subsubsection{Comparison of the two compression tests}

First, the pin-ended bucking test results are compared to those from a standard compression test (ISO 14126, Method 2) on specimens taken from the same C/PA6 panel. The results obtained are shown in Table 4. 
Table 4 : Results from compression tests for C/PA6 specimens with associated coefficient of variation

\begin{tabular}{cccc}
\hline Test Method & $\boldsymbol{\sigma}_{\text {1comp }}[\mathbf{M P a}]$ & $\boldsymbol{\varepsilon}_{\mathbf{1 c o m p}}[\mathbf{\%}]$ & $\mathbf{E}_{\mathbf{1 c o m p}}[\mathbf{G P a}]$ \\
\hline Pin-ended Buckling & $1385 \pm 7 \%$ & $1.53 \pm 7 \%$ & $89.7 \pm 2 \%$ \\
Uniaxial compression & $513 \pm 13 \%$ & $0.57 \pm 30 \%$ & $91.2 \pm 1 \%$ \\
\hline
\end{tabular}

While stiffness values are very similar, within experimental scatter, it is clear that the strengths obtained from these tests are highly dependent on the test fixture. There is a ratio of around 3 between the compressive strength values for these two tests. It can also be noted that the compressive modulus is lower than the tensile modulus, approximately $80 \%$ of the latter. There has been some discussion of the analysis of the pin-ended buckling test in published papers. While compressive strain to failure is measured directly, stresses are usually determined using Equation 3. An example of the results from strain gauges bonded on each side of a C/PA6 specimen shown below as a plot of the applied bending moment, Figure 9, versus strain measured both on the tension and compression sides.

Figure 9 : Applied bending moment versus strain on both specimen faces, pin-ended buckling test on C/PA6 specimens

The results show the presence of a strain gradient through the specimen thickness and the more nonlinear response in compression at high strain. The tensile and compressive strains at failure are 1.27 and $-1.45 \%$ respectively here, leading to a strain gradient of $1.36 \% / \mathrm{mm}$. The compressive strain at failure for C/PA6 is slightly lower than values given by Wisnom and Atkinson for carbon/epoxy at a similar strain gradient in [40]. 
From these results, we can see that there is a $14 \%$ difference between the absolute tensile and compressive strains at failure. Equation 3 can be used to obtain a compressive stress at failure but it is based on analysis of a beam with identical tension and compression behaviour. The increasing difference in modulus values will affect the position of the neutral axis and hence the calculation of the stresses. An estimation of the effect of the nonlinear compressive behaviour can be made using the method proposed by Montagnier and Hochard. [17] and Wisnom et al. [22] based on fitting the stress versus strain plots in pure tension (Equation 6) and compression tests Equation 7):

$$
\begin{aligned}
\sigma_{\text {tension }} & =E_{\text {tension }}(1+\alpha \varepsilon) \varepsilon \\
\sigma_{\text {compression }} & =E_{\text {compression }}(1+\beta \varepsilon) \varepsilon
\end{aligned}
$$

where $\alpha$ and $\beta$ are respectively the non linear parameters in tension and compression. The values of $\alpha$ and $\beta$ were identified on the experimental data and are respectively equal to 4.8 and 18 . It is worth noting that Equation 7 is based on an identification of compressive tests at low strains $(0.5 \%$ compared to $1.5 \%$ in pin-ended buckling tests). As stated by Wisnom [23] on C/epoxy specimens, it is thought that Equation 7 can be used at higher strains. The modulus values were taken as the mean modulus value for pure tension and compression tests in the dry state and are respectively equal to $105 \mathrm{GPa}$ and $91.2 \mathrm{GPa}$. For the pin-ended buckling test, Equation 7 is coupled with the experimental compressive strain measurements to calculate the compressive stress. This leads to a compressive stress of around $70 \%$ of the value calculated using Equation 3. A more detailed stress analysis could be performed numerically, but here the test is simply used to evaluate how moisture affects compressive strains and estimated stresses at failure, so the latter will be referred to as "apparent compressive strength".

The high apparent compressive strength at failure (higher than $1000 \mathrm{MPa}$ ) for the C/PA6 confirms that it is a suitable candidate compared to the C/PEEK counterpart. Similar tests (pin-ended buckling) were carried out on unidirectional C/PEEK laminates, and yielded an apparent compressive strength of $1645 \pm 29 \mathrm{MPa}$. Even though the results are a little higher for the C/PEEK counterpart, the fibre volume fraction is also higher by $10 \%$.

These two compression tests are clearly different, the stress states across the specimen sections are not the same and the debate on which test is most appropriate remains open. In the remainder of the work presented here the pin-ended buckling test was retained for practical reasons: first, it allowed exactly the same specimen geometry to be used for the tension and compression tests. (The standard compression test dimensions are smaller, so aging times would need to be adjusted to reach the same saturation level). Second, the test specimen is simpler to prepare, as only one strain gauge is needed on the compression side (two are required for the standard test). 


\subsubsection{Effect of water on the compressive properties}

The pin-ended buckling test was used to investigate the effect of water aging on the compressive properties. First, pin-ended buckling tests were performed on C/PEEK specimens before and after saturation in sea water at $80^{\circ} \mathrm{C}$ (approximately 2 months "e aging). Results showed no reduction in terms of strength at failure, strain at failure and modulus. Strengths at failure were $1685 \pm 29 \mathrm{MPa}$ and $1783 \pm 245$ before and after aging respectively. Modulus was $117.5 \pm 4.5 \mathrm{GPa}$ before aging and $121.4 \pm 3.2 \mathrm{GPa}$ after aging.

It is clear that for the C/PEEK composite the apparent compressive strength and the modulus are not sensitive to aging. However, the results are quite different for C/PA6. The aging conditions are exactly the same as for tensile tests. Examples of stress-strain plots are presented in Figure 10

Figure 10 : Apparent compression stress-strain plots for C/PA6 specimens tested with the pin-ended buckling test fixture under several aging conditions

These plots show that there is a large decrease in the failure strain when the specimen is tested with higher uniform water contents. The apparent stress at failure and the value corrected for non-linearity are respectively divided by 3 and 2 between the dry and the sea water saturated specimens. However, the effect on the modulus is very limited. 
Figure 11 presents the apparent and corrected compressive strengths obtained as a function of water content.

Figure 11: Apparent and corrected compressive strength as a function of water content, using Equation 3 and Equation 7

This figure highlights the fact that the compressive strength decreases by approximately $50 \%$ from 0 to $1 \%$ water content. Above this water level, the compressive strength only decreases by $10 \%$ until saturation. It is interesting to note that the difference between the apparent and the corrected compressive strengths are lower at increasing water levels. In Figure 10, we have seen that the stiffness in the range from 0.1 to $0.3 \%$ of the C/PA6 
did not evolve with aging. At increasing water levels, the strain at failure is lower. Therefore, since the non linearity depends on the strain level, its effect is much lower at lower strains.

Then, the failure modes of the specimens subjected to different humidity conditions and tested in compression were very different. The dry specimens and those aged at $33 \%$ humidity broke in a very brittle manner (the specimen broke suddenly in two different pieces) unlike those aged at $75 \%$ humidity and immersed in sea water, which failed in a very ductile manner. Concerning the specimens aged at $63 \%$ humidity, four out of five samples broke in a ductile manner and one in a brittle manner. It should be noted that Fukuda [21] associated this failure mode to compressive failures. The two different failure modes observed are shown in Figure 12.

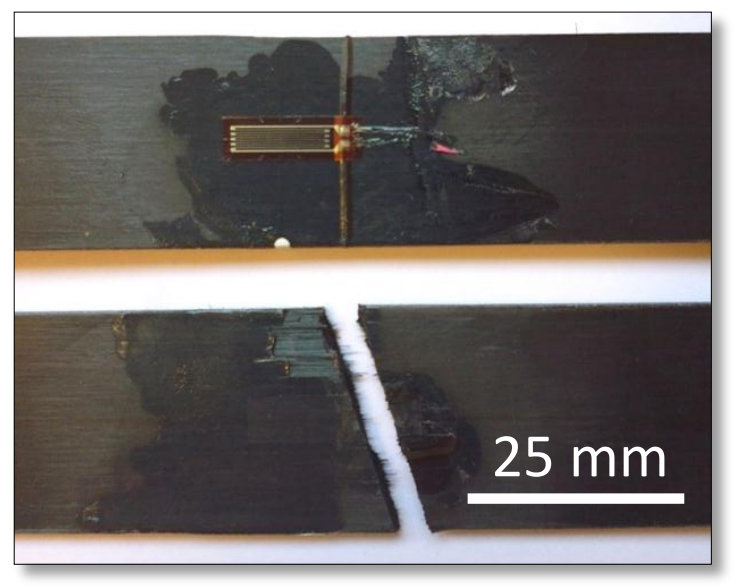

Figure 12 : Upper image: ductile failure mode of a specimen saturated in sea water. Lower image: brittle failure mode for a dry specimen

The desorption process was also investigated, to determine whether the properties were reversible. To do so, several samples were immersed until saturation and were then dried until they reached their initial dry mass. Afterwards, these same samples were tested in compression (pin ended buckling test). Results are shown in Table 5 .

Table 5 : Effect of desorption on the compressive properties with associated coefficient of variation

\begin{tabular}{cccc}
\hline Conditioning & $\boldsymbol{\sigma}_{\mathbf{1 f}}[\mathbf{M P a}]$ & $\boldsymbol{\varepsilon}_{\mathbf{1 f}}[\%]$ & $\mathbf{E}_{\mathbf{1}}[\mathbf{G P a}]$ \\
\hline Dry & $1385 \pm 7 \%$ & $1.53 \pm 7 \%$ & $89.7 \pm 2 \%$ \\
Saturated in sea water & $571 \pm 6 \%$ & $0.62 \pm 5 \%$ & $82.1 \pm 6 \%$
\end{tabular}


The apparent compressive strength properties are mostly recovered after the desorption process, suggesting that plasticisation is the main aging mechanism, even though they are not fully reversible. The mean strength loss is around $15 \%$ after aging and re-drying, but the modulus returns to its initial dry value. The differences found in compressive strength may be due to a permanent decrease in interface quality after aging, though experimental variation is also significant. Moreover, as stated earlier, the compressive strength is known to depend on the matrix shear modulus. Therefore, a lower compressive strength could also be caused by a lower shear modulus after aging. Unfortunately, such tests after aging have not been performed as the neat matrix polymer was not available.

Finally, all the values for tension, compressive, shear properties and glass transition temperatures in the dry and water saturated states are grouped in Table 6.

Table 6 : Values of tension, compressive, shear properties and glass transition temperatures in the dry and water saturated states with associated coefficient of variation

\begin{tabular}{|c|c|c|c|c|c|c|}
\hline \multicolumn{2}{|c|}{$\mathbf{M}(\mathbf{t})$} & 0 & $0.31 \pm 3 \%$ & $1.11 \pm 4 \%$ & $1.36 \pm 2 \%$ & $3.01 \pm 1 \%$ \\
\hline \multicolumn{2}{|c|}{$\mathbf{T}_{\mathrm{g}}\left({ }^{\circ} \mathrm{C}\right)$} & $66 \pm 4 \%$ & $54 \pm 7 \%$ & $28 \pm 5 \%$ & $19 \pm 3 \%$ & -12 \\
\hline \multicolumn{2}{|c|}{$E_{1 \text { tension }}(\mathbf{G P a})$} & $105 \pm 5 \%$ & $106 \pm 3 \%$ & $105 \pm 2 \%$ & $106 \pm 2 \%$ & $111 \pm 2 \%$ \\
\hline \multicolumn{2}{|c|}{$\sigma_{1 \text { tension }}(\mathrm{MPa})$} & $1808 \pm 7 \%$ & / & / & / & l \\
\hline \multicolumn{2}{|c|}{$v_{12}$} & $0.36 \pm 8 \%$ & $0.38 \pm 3 \%$ & $0.40 \pm 5 \%$ & $0.43 \pm 5 \%$ & $0.42 \pm 5 \%$ \\
\hline \multicolumn{2}{|c|}{$G_{12}(G P a)$} & $2.4 \pm 4 \%$ & $2.1 \pm 10 \%$ & $1.3 \pm 8 \%$ & $1.3 \pm 8 \%$ & $1.2 \pm 8 \%$ \\
\hline \multicolumn{2}{|c|}{$\tau_{12}(\mathrm{MPa})$} & $37 \pm 4 \%$ & $33 \pm 2 \%$ & $23 \pm 5 \%$ & $21 \pm 3 \%$ & $21 \pm 4 \%$ \\
\hline \multicolumn{2}{|c|}{$\mathrm{E}_{2}(\mathrm{GPa})$} & $5,8 \pm 9 \%$ & $5,5 \pm 6 \%$ & $4,0 \pm 6 \%$ & $3,5 \pm 4 \%$ & $2,3 \pm 4 \%$ \\
\hline \multicolumn{2}{|c|}{$\sigma_{2}(\mathrm{MPa})$} & $25 \pm 8 \%$ & $27 \pm 9 \%$ & $21 \pm 5 \%$ & $19 \pm 5 \%$ & $17 \pm 3 \%$ \\
\hline \multirow{2}{*}{$\begin{array}{l}E_{1 \text { comp }} \\
\text { (GPa) }\end{array}$} & $\mathbf{P C} *$ & $91,2 \pm 1 \%$ & / & l & l & l \\
\hline & PeB** & $89,7 \pm 2 \%$ & $89,9 \pm 6 \%$ & $89,6 \pm 1 \%$ & $83,9 \pm 8 \%$ & $82,1 \pm 6 \%$ \\
\hline \multirow{2}{*}{$\varepsilon_{1 \text { comp }}(\%)$} & $\mathbf{P C}^{*}$ & $0,57 \pm 30 \%$ & l & l & l & l \\
\hline & PeB** & $1,53 \pm 7 \%$ & $1,24 \pm 14 \%$ & $0,79 \pm 13 \%$ & $0,73 \pm 7 \%$ & $0,62 \pm 5 \%$ \\
\hline \multirow{2}{*}{$\begin{array}{l}\sigma_{1 \text { comp }} \\
(\mathrm{MPa})\end{array}$} & PC* & $513 \pm 13 \%$ & l & l & l & l \\
\hline & $\begin{array}{l}\text { Apparent } \\
\text { PeB** }\end{array}$ & $1385 \pm 7 \%$ & $1075 \pm 14 \%$ & $719 \pm 12 \%$ & $643 \pm 8 \%$ & $571 \pm 6 \%$ \\
\hline
\end{tabular}




\begin{tabular}{|c|c|c|c|}
\hline $\begin{array}{c}\text { Corrected } \\
\text { PeB** }\end{array}$ & $1004 \pm 10 \%$ & $880 \pm 9 \%$ & $601 \pm 13 \%$ \\
\hline
\end{tabular}

3.5. $\mathrm{T}_{\mathrm{g}}$ related behaviour

Most of the results presented earlier seem to follow a common behaviour, i.e. the property of interest changes quickly initially until the water content reaches $1 \%$. For water contents higher than $1 \%$, the property of interest tends to stabilise. As indicated in the Introduction, the compressive behaviour depends on the matrix response, so one might expect a similar change in all matrix-dependent properties as water enters the composite. In order to investigate this, all the matrix dependent wet properties have been normalised (shear modulus, shear strength, transverse tensile strength, transverse tensile modulus, apparent compressive strength and corrected compressive strength). These are plotted as a function of the water content, in Figure 13.

Figure 13 : Normalised properties as a function of the water content for C/PA6

This figure suggests that all the properties are governed by the same behaviour. Two trends are observed. First, the properties decrease by approximately $45 \%$ from 0 to $1 \%$ water content and then decrease by a further $10 \%$ until complete saturation. Two different slopes are identified. This is a very useful result, as it enables all matrix dominated properties to be expressed to a first approximation by two simple equations for each property of interest, Equation 8 and Equation 9. These can be expressed as follows:

$$
\text { For } M(t)<1 \%, \text { Normalised property }=C_{1} \times M(t)+1
$$




$$
\text { For } M(t)>1 \%, \text { Normalised property }=C_{2}
$$

For each property, those two constants are shown in Table 7.

Table 7 : Constants $\mathrm{C}_{1}$ and $\mathrm{C}_{2}$ for each property of interest

\begin{tabular}{ccc}
\hline & $\mathbf{C}_{\mathbf{1}}$ & $\mathbf{C}_{\mathbf{2}}$ \\
\hline$\tau_{12}$ & -0.3503 & 0.5849 \\
Apparent $\sigma_{\text {comp }}$ & -0.4554 & 0.4652 \\
Corrected $\sigma_{\text {comp }}$ & -0.3654 & 0.5591 \\
$\sigma_{2}$ & -0.1884 & 0.7026 \\
$\mathrm{E}_{2}$ & -0.2732 & 0.5644 \\
$\mathrm{G}_{12}$ & -0.4131 & 0.5277 \\
\hline
\end{tabular}

These can be used directly in the design process in combination with diffusion equations to simply establish local properties as a function of local water content. Given the magnitude of the changes, for C/PA6 composites taking account of water ingress is essential (while for C/PEEK this effect may be neglected). It should be noted that the two equations that were just suggested are only valid for tests conducted at $21^{\circ} \mathrm{C}$. For the application of interest, the temperature ranges from 4 to $15^{\circ} \mathrm{C}$ and this has to be taken into account.

It was also shown above that the compressive failure modes changed during aging. Below $1 \%$ water content, the failures were in brittle mode and after $1 \%$, these were in ductile mode. This indicates that there is a change in mechanism at approximately $1 \%$ water content. The glass transition temperatures were determined in section 3.2 as a function of water content and were found to decrease from $66^{\circ} \mathrm{C}$ in the dry state to $-12^{\circ} \mathrm{C}$ when the material was fully saturated in water. This is a well-known effect for PA6 but is an exceptionally large 
change in a composite. When tests are performed at $21^{\circ} \mathrm{C}$ on a specimen fully saturated in water, the test is being conducted above the glass transition temperature of the matrix. Therefore, the matrix exhibits a rubbery, ductile behaviour. On the contrary, a test conducted at $21^{\circ} \mathrm{C}$ on a dry specimen is performed below the glass transition temperature of the polymer, in the glassy state, and the composite exhibits a brittle behaviour. An alternative representation of the normalised properties is as a function of $\left(\mathrm{T}-\mathrm{T}_{\mathrm{g}}\right)$ with $\mathrm{T}$ being the temperature at which the test was conducted, Figure 14. This parameter allows us to determine whether a test is being performed below or above the glass transition temperature of a specimen saturated in a certain environment.

Figure 14 : Normalised property plotted as a function of a $\mathrm{T}-\mathrm{T}_{\mathrm{g}}$

The last two figures reveal equivalence between glass transition temperature and water content. Then, the transverse modulus has been determined here as a function of temperature by DMA. The latter was then plotted as a function of $\mathrm{T}-\mathrm{T}_{\mathrm{g}}$ in Figure 15, together with the transverse modulus saturated at different conditions. 
Figure 15 : Transverse modulus as a function of $\mathrm{T}^{-} \mathrm{T}_{\mathrm{g}}$ for tests conducted in temperature (DMA) and in wet conditions

It is clear that a good agreement exists between these two results. Therefore, it seems that the matrix dominated properties of C/PA6 laminates are governed by the same parameter, which is the difference between the test temperature and the glass transition temperature. This provides a powerful tool to predict composite behaviour over a wide range of conditions. Finally, it was shown in Figure 6.b that the Poisson"s ratio increased with water content and stabilised for water contents above $1 \%$, i.e. when the $\mathrm{T}_{\mathrm{g}}$ drops below the testing temperature. A similar trend was observed previously for tests at different temperatures [50], [51]. This increase in Poisson"s ratio was associated with the transition to a more rubbery behaviour as water enters and $\mathrm{T}_{\mathrm{g}}$ drops. Rubbers are usually considered to be materials which show no volume change during elastic deformation with a Poisson"s ratio close to 0.5 [52]. A higher Poisson"s ratio is therefore obtained when the glass transition is far lower than the test temperature.

\section{Conclusion}

This paper presents a unique set of data relating the tensile and compressive properties of C/PA6 to water content. Water has a very negative effect on the matrix dominated mechanical properties of these composites which are reduced by over $50 \%$. This loss in properties has been linked to the large decrease in the glass transition temperature (from $66^{\circ} \mathrm{C}$ in the dry state to $-12^{\circ} \mathrm{C}$ when saturated with sea water). An empirical relationship between the mechanical properties and the water content and the $\mathrm{T}-\mathrm{T}_{\mathrm{g}}$ parameter has been proposed, 
which can be used to account for environmental changes in matrix-dominated properties. The results were compared to a $\mathrm{C} / \mathrm{PEEK}$ reference, for which water saturation had no effect on the mechanical properties.

Finally, this work has considered tests on specimens containing homogenous amounts of water.

However, the overall aim of the project is to be able to model the water diffusion in thick C/PA6 cylinders and its effect on the mechanical properties (implosion pressure). Therefore, future work includes validating the proposed empirical law on specimens with through-thickness water profiles, taking into account the water diffusion kinetics and temperature.

\section{Acknowledgments}

The authors would like to thank Eric Lolive and Thomas Bonnemains from the IUT of Brest for their help in processing the different panels. This project is funded by an InterCarnot project between IFREMEREDROME and CETIM, Nantes.

\section{References}

[1] P. Davies, „Chapter 6 - Behavior of marine composite materials under deep submergence Applications of Advanced Fibre-Reinforced Composites, Edited by Summerscales, J.Graham-Jones J.Woodhead Publishing, 2016, pp. 125-145.

[2] C. S. Smith, „Design of submersible pressure hulls in composite materialse, Mar. Struct., vol. 4, no. 2, pp. 141-182, 1991.

[3] M. J. Hinton, A. S. Kaddour, and P. D. Soden, Failure Criteria in Fibre Reinforced Polymer Composites: The World-Wide Failure Exercise. Elsevier, 2004.

[4] M. B. Gruber, M. A. Lamontia, M. A. Smoot, and V. Peros, ,Buckling Performance of Hydrostatic Compression-Loaded 7-Inch Diameter Thermoplastic Composite Monocoque Cylinders 'e, J. Thermoplast. Compos. Mater., vol. 8, no. 1, pp. 94-108, Jan. 1995.

[5] G. F. Leon, J. Hall, J. J. Kelly, and R. Bohlmann, „Design and testing of in-situ consolidated thick high performance thermoplastics , in 12 th International Conference on Composite Materials, Paris, 1999.

[6] P. Davies, „Thermoplastic Composite Cylinders for Underwater Applications ${ }^{\mathrm{ee}}$, J. Thermoplast. Compos. Mater., vol. 18, no. 5, pp. 417-443, Sep. 2005.

[7] C. Soutis, ,Measurement of the Static Compressive Strength of Carbon-Fibre/Epoxy Laminates ${ }^{\text {,e }}$ Composite Science and Technology, pp. 373-392, 1991.

[8] P. Berbinau, C. Soutis, and I. A. Guz, ,Compressive failure of 0 unidirectional carbon-fibre-reinforced plastic (CFRP) laminates by fibre microbucklinge, Compos. Sci. Technol., vol. 59, no. 9, pp. 1451-1455, 1999.

[9] W. Hart, R. Aoki, H. Bookholt, P. T. Curtis, I. Krober, N. Marks, and P. Sigety, „Garteur compression behavior of advanced CFRP'e, Workshop on Advanced Composites in Military Aircraft, San Diego CA, Oct. 1991.

[10] ASTM D3410, „Test Method for Compressive Properties of Polymer Matrix Composite Materials with Unsupported Gage Section by Shear Loading"e, ASTM International, 2008.

[11] ISO 14126, „Composites plastiques renforcés de fibres - Détermination des caractéristiques en compression dans le plan', Norme Eur., 1999.

[12] ASTM D695, „Test Method for Compressive Properties of Rigid Plastics ${ }^{e e}$ ASTM International, 2010. 
[13] ASTM D6641, „Test Method for Compressive Properties of Polymer Matrix Composite Materials Using a Combined Loading Compression (CLC) Test Fixture , ASTM International, 2014.

[14] A. J. Barker and V. Balasundaram, ,Compression testing of carbon fibre-reinforced plastics exposed to humid environments"e, Composites, vol. 18, no. 3, 1987.

[15] J. . Haberle and F. L. Matthews, ,An improved technique for compression testing of unidirectional fibrereinforced plastics; development and results", Composites, vol. 25, no. 5, 1994.

[16] E. M. Odom and D. F. Adams, ,Failure modes of unidirectional carbon/epoxy composite compression specimens ', Composites, vol. 21, no. 4, 1990.

[17] O. Montagnier and C. Hochard, ,Compression Characterization of High-modulus Carbon Fiberse, $J$. Compos. Mater., vol. 39, no. 1, pp. 35-49, Jan. 2005.

[18] N. Carbajal and F. Mujika, ,Determination of compressive strength of unidirectional composites by threepoint bending testse, Polym. Test., vol. 28, no. 2, pp. 150-156, Apr. 2009.

[19] N. V. De Carvalho, S. T. Pinho, and P. Robinson, ,An experimental study of failure initiation and propagation in 2D woven composites under compression", Compos. Sci. Technol., vol. 71, no. 10, pp. 1316-1325, Jul. 2011

[20] E. Vittecoq, ,Sur le comportement en compression des composites stratifiés carbone-epoxy ${ }^{\mathrm{ee}}$, Paris 6, Paris, 1991.

[21] H. Fukuda, „A new bending test method of advanced composites ${ }^{\text {ee }}$ Exp. Mech., vol. 29, no. 3, pp. 330-335, 1989.

[22] M. R. Wisnom, ,On the high compressive strains achieved in bending tests on unidirectional carbonfibre/epoxyee, Compos. Sci. Technol., vol. 43, no. 3, pp. 229-235, 1992.

[23] M. R. Wisnom, ,The effect of specimen size on the bending strength of unidirectional carbon fibre-epoxy ${ }^{e e}$, Compos. Struct., vol. 18, no. 1, pp. 47-63, 1991.

[24] I. Grandsire-Vinçon, „Compression des composites unidirectionnels: Méthode d'essai et approche micromécanique, $\mathrm{PhD}$ thesis (in french) ENS Cachan, 1993.

[25] S. W. Yurgartis and S. S. Sternstein, ,A micrographic study of bending failure in five thermoplasticcarbon fibre composite laminatese, J. Mater. Sci., vol. 23, no. 5, pp. 1861-1870, 1988.

[26] J. A. Grape and V. Gupta, „The effect of temperature on the strength and failure mechanisms of a woven carbon/polyimide laminate under compression"e, Mech. Mater., vol. 30, no. 3, pp. 165-180, Nov. 1998.

[27] B. W. Rosen, „Mechanics of composite strengthening. “ 01-Jan-1965.

[28] R. J. Lee, „Compression strength of aligned carbon fibre-reinforced thermoplastic laminates ${ }^{\text {ee }}$ Composites, vol. 18 , no. 1, pp. 35-39, 1987.

[29] A. S. Argon, „Fracture of Composites ${ }^{\mathrm{ee}}$, in Treatise of materials science and technology, vol. 1, New York: Academic Press, 1972, pp. 79-114.

[30] C. Soutis and D. Turkmen, „Moisture and Temperature Effects of the Compressive Failure of CFRP Unidirectional Laminates ${ }^{e e}$, J. Compos. Mater., vol. 31, no. 8, pp. 832-849, Jan. 1997.

[31] G. Zhang, R. A. Latour Jr, J. M. Kennedy, H. Del Schutte Jr, and R. J. Friedman, „Long-term compressive property durability of carbon fibre-reinforced polyetheretherketone composite in physiological saline ${ }^{\text {ee }}$, Biomaterials, vol. 17, no. 8, pp. 781-789, 1996.

[32] E. L. McKague, J. D. Reynolds, and J. E. Halkias, ,Swelling and glass transition relations for epoxy matrix material in humid environments ${ }^{\text {ee }}$ J. Appl. Polym. Sci., vol. 22, no. 6, pp. 1643-1654, Jun. 1978.

[33] Y. J. Weitsman, Fluid Effects in Polymers and Polymeric Composites. Boston, MA: Springer US, 2012.

[34] M. Broudin, P. Y. Le Gac, V. Le Saux, C. Champy, G. Robert, P. Charrier, and Y. Marco, ,Water diffusivity in PA66: Experimental characterization and modeling based on free volume theorye, Eur. Polym. J., vol. 67, pp. 326-334, Jun. 2015.

[35] C.-H. Shen and G. S. Springer, ,Effects of Moisture and Temperature on the Tensile Strength of Composite Materialse, J. Compos. Mater., vol. 11, no. 1, pp. 2-16, Jan. 1977.

[36] N. Tual, N. Carrere, P. Davies, T. Bonnemains, and E. Lolive, „Characterization of sea water ageing effects on mechanical properties of carbon/epoxy composites for tidal turbine blades ${ }^{\text {ec }}$ Compos. Part Appl. Sci. Manuf., vol. 78, pp. 380-389, Nov. 2015.

[37] I. M. Daniel and O. Ishai, Engineering Mechanics of Composite Materials. Oxford University Press, 2006.

[38] J. Mark, Polymer Data Handbook. Oxford University Press, 1999.

[39] M. R. Wisnom, J. W. Atkinson, and M. I. Jones, ,Reduction in compressive strain to failure with increasing specimen size in pin-ended buckling tests "e, Compos. Sci. Technol., vol. 57, no. 9, pp. 13031308, Jan. 1997.

[40] M. R. Wisnom and J. W. Atkinson, ,Constrained buckling tests show increasing compressive strain to failure with increasing strain gradient”, Compos. Part Appl. Sci. Manuf., vol. 28, no. 11, pp. 959-964, Jan. 1997.

[41] L. Greenspan and others, „Humidity fixed points of binary saturated aqueous solutions ${ }^{\text {ee }}, J$. Res. Natl. Bur. Stand., vol. 81, no. 1, pp. 89-96, 1977. 
[42] C. Thomas, ,Étude des mécanismes d'endommagement des composites fibres de carbone / matrice polyamide : application à la réalisation de réservoirs de stockage de gaz sous haute pression de type IV ${ }^{c e}$, $\mathrm{PhD}$ Thesis (in french) École Nationale Supérieure des Mines de Paris, 2011.

[43] R. T. D. Prabhakaran and H. Toftegaard, ,Environmental effect on the mechanical properties of commingled-yarn-based carbon fibre/polyamide 6 composites $^{\text {ee }}$ J. Compos. Mater., vol. 48, no. 21, pp. 2551-2565, Sep. 2014.

[44] E. Botelho, „Mechanical behavior of carbon fiber reinforced polyamide composites ${ }^{e c}$ Compos. Sci. Technol., vol. 63, no. 13, pp. 1843-1855, Oct. 2003.

[45] C. El-Mazry, O. Correc, and X. Colin, ,A new kinetic model for predicting polyamide 6-6 hydrolysis and its mechanical embrittlement", Polym. Degrad. Stab., vol. 97, no. 6, pp. 1049-1059, Jun. 2012.

[46] C.-H. Shen and G. S. Springer, ,Moisture Absorption and Desorption of Composite Materials ${ }^{\text {ee }}$,J. Compos. Mater., vol. 10, no. 1, pp. 2-20, Jan. 1976.

[47] E. Picard, J.-F. Gérard, and E. Espuche, „Water transport properties of polyamide 6 based nanocomposites prepared by melt blending: On the importance of the clay dispersion state on the water transport properties at high water activityee, J. Membr. Sci., vol. 313, no. 1-2, pp. 284-295, Apr. 2008.

[48] R. Taktak, N. Guermazi, J. Derbeli, and N. Haddar, ,Effect of hygrothermal aging on the mechanical properties and ductile fracture of polyamide 6: Experimental and numerical approaches ${ }^{e e}$, Eng. Fract. Mech., vol. 148, pp. 122-133, Nov. 2015.

[49] V.-T. Do, H.-D. Nguyen-Tran, and D.-M. Chun, ,Effect of polypropylene on the mechanical properties and water absorption of carbon-fiber-reinforced-polyamide-6/polypropylene composite ${ }^{\mathrm{e}}$, Compos. Struct., vol. 150, pp. 240-245, Aug. 2016.

[50] S. Pandini, ,Time and temperature effects on Poisson's ratio of poly(butylene terephthalate) ${ }^{\mathrm{ee}}$, Express Polym. Lett., vol. 5, no. 8, pp. 685-697, May 2011.

[51] S. Pandini and A. Pegoretti, ,Time, temperature, and strain effects on viscoelastic Poisson 's ratio of epoxy resins ${ }^{\text {ee }}$ Polym. Eng. Sci., vol. 48, no. 7, pp. 1434-1441, Jul. 2008.

[52] D. W. van Krevelen and K. te Nijenhuis, Properties of Polymers: Their Correlation with Chemical Structure; their Numerical Estimation and Prediction from Additive Group Contributions. Elsevier, 2009. 